\title{
Analysis of microstructural properties of IN 718 after high speed forging
}

\author{
Lars Renhof $^{1}$, Christian Krempaszky ${ }^{1}$, Ewald Werner $^{1}$, Martin Stockinger ${ }^{2}$ \\ ${ }^{1}$ Lehrstuhl für Werkstoffkunde und Werkstoffmechanik / Christian-Doppler Laboratorium, \\ Technical University Munich, 85747 Garching/Germany \\ ${ }^{2}$ Böhler Schmiedetechnik, 8605 Kapfenberg/Austria
}

Keywords: IN 718, $\gamma^{\prime \prime}$-phase, high strain rate forming, TTT-diagram

\begin{abstract}
The precipitation of the $\gamma^{\prime \prime}$-Phase is the key to the excellent mechanical properties of IN 718 . These can be improved by forging the material on a screw press (high strain rate forming) instead of a hydraulic press (low strain rate forming) [1]. The increase in hardness cannot be explained by grain size effects but is due to finely dispersed $\gamma^{\prime \prime}$-particles found in the as-forged material. The time-temperature-transformation-diagram of IN 718 [2] predicts no precipitation of the $\gamma^{\prime \prime}$-phase during cooling from the forging temperature. Therefore, it seems that the common TTT-diagram for IN 718 as reported in [2] is not applicable to the material exposed to high strain rates as the precipitates develop much earlier than predicted. In this work investigations on the effects of high strain rate forging on the precipitation behavior of IN 718 are presented. A modified TTT-diagram is suggested for IN 718 exposed to high strain rates.
\end{abstract}

\section{Introduction}

INCONEL 718 (IN 718, see Table I) is a nickel-base superalloy frequently employed for structural parts in turbines due to its excellent strength at elevated temperatures. Its face centered cubic (fcc) matrix is mainly strengthened by precipitates of the meta stable Nb-rich $\gamma^{\prime \prime}$-phase $\left(\mathrm{Ni}_{3} \mathrm{Nb}\right)$. This phase has a body centered tetragonal (bct) structure and is semicoherent to the matrix with a size-misfit of approximately 3-5\% [3-5]. Furthermore, the stable $\left(\mathrm{Ni}_{3} \mathrm{Nb}\right) \delta$-phase is present in the material besides small amounts of carbides and nitrides. Usually, structural parts made from IN 718 are forged followed by a heat treatment (aging). There are two different types of aging procedures currently used, namely the standard procedure (air cooling from forging temperature to room temperature, annealing for one hour at $980^{\circ} \mathrm{C}$, air cooling to room temperature again and afterwards heating up to $718^{\circ} \mathrm{C}$ ) and direct aging, where the material is water quenched to room temperature after forging and reheated directly to $718^{\circ} \mathrm{C}$. After reaching $718^{\circ} \mathrm{C}$, the material is aged at $718^{\circ} \mathrm{C}$ for 8 hours in a furnace under standard atmosphere. Then, the furnace is cooled down to $621^{\circ} \mathrm{C}$ at a cooling rate of $50 \mathrm{~K} / \mathrm{h}$. The second step of aging at $621^{\circ} \mathrm{C}$ lasts another 8 hours, see Figure 1 .

Table I: Chemical composition of IN 718, in wt-\%

\begin{tabular}{|c|c|c|c|c|c|c|}
\hline $\mathrm{Ni}$ & $\mathrm{Fe}$ & $\mathrm{Cr}$ & $\mathrm{Nb}$ & $\mathrm{Mo}$ & $\mathrm{Ti}$ & $\mathrm{Al}$ \\
\hline 52 & 19 & 19 & 5.3 & 3.1 & 0.95 & 0.55 \\
\hline
\end{tabular}




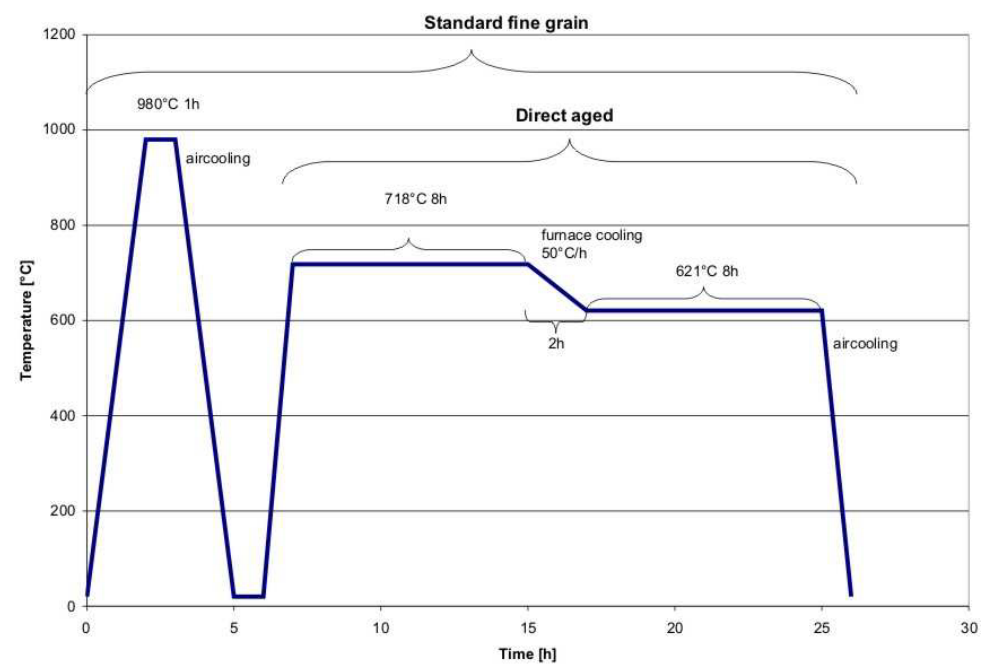

Figure 1: Heat treatment of IN 718 after the forging process (the dashed line represents the heating from room temperature in the standard heat treatment).

Investigations regarding the mechanical properties of forged components show an increase of strength, if the material is forged on a screw press $[1,6]$ instead on a hydraulic press (see Figure 2). The beneficial influence of high strain rates on the mechanical properties cannot be explained simply by grain refinement or a higher dislocation density [6-8]. Therefore it is assumed, that the high strain rate influences the precipitation behaviour of the $\gamma^{\prime \prime}$-phase. In this work the time-temperature-precipitation-behaviour of the $\gamma^{\prime \prime}$-phase in forged IN 718 is investigated. Therefore, as-forged specimens are heat treated and the development of the $\gamma^{\prime \prime}$-phase during heat treatment is observed using a transmission electron microscope. The mechanical properties are monitored by measuring Vickers hardness (HV).

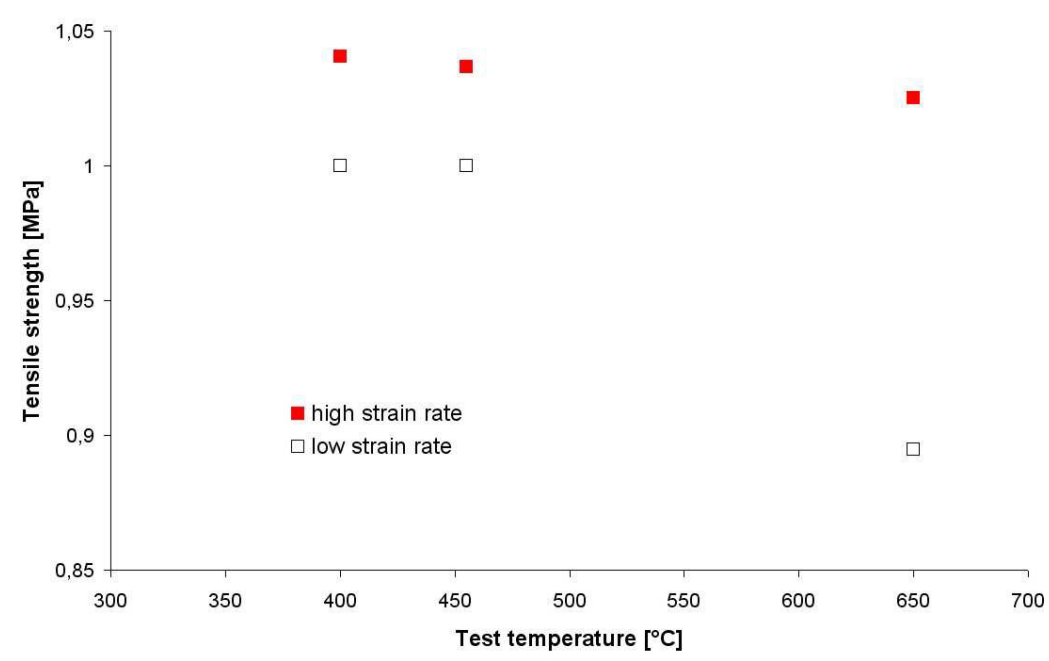

Figure 2: Comparison of the tensile strength of fully heat treated IN 718 specimens exposed to high and low strain rates at different test temperatures. 


\section{Experimental}

Two turbine discs were forged either on a hydraulic press (low strain rates) or on a screw press (high strain rates). Both billets were heated to forging temperature, forged to a mean degree of deformation of $\varphi=0.5$ (logarithmic reduction of global billet height), reheated to forging temperature and forged to $\varphi=1.0$ before water quenching. This state is termed asforged. For comparison, two billets were air cooled after forging (again either on a hydraulic or a screw press).

Specimens taken from the as-forged billets are heat treated at $718^{\circ} \mathrm{C}$ for $2,4,8,20$ and 50 hours followed by water quenching to freeze the microstructure.

Quantitative analyses using light microscopy were performed to estimate the grain size of the matrix and the volume fraction of the $\delta$-phase. For this purpose the specimens were ground, polished and etched. As-forged specimens were etched with Beraha III [9]. For the heat treated material potentiostatic etching leads to satisfying results [10].

Sub-micrometer sized precipitates were analyzed using transmission electron microscopy (TEM). Thin foils were cut from the specimens and thinned electrolytically. Brightfield imaging and diffraction analyses were performed on these foils.

The hardness is used to characterize the strength properties of the materials subjected to the different processing routes. The hardness values are determined with Vickers-hardness measurements with a testload of $10 \mathrm{kp}$ (HV 10).

All analysis was undertaken on specimens cut from the region in the turbine disc billet marked in Figure 3.

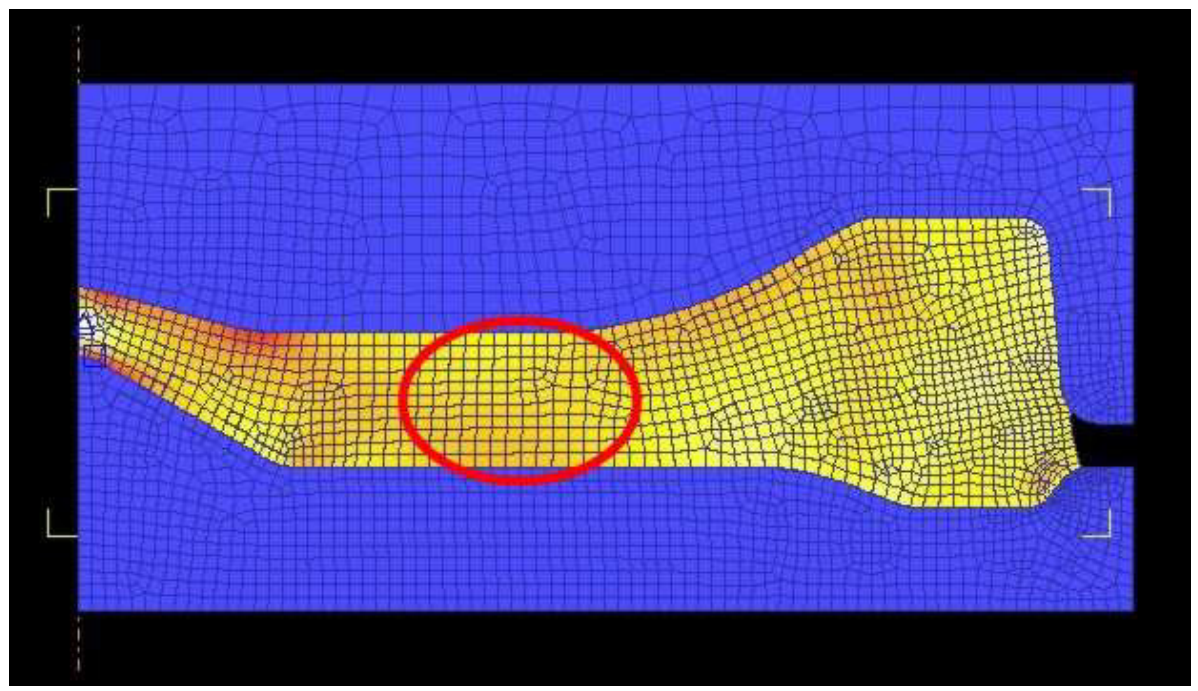

Figure 3: Half-cross section of a turbine disk billet (Finite element calculation). From the marked region the specimens for microstructural analysis and hardness measurement are taken.

\section{Results and Discussion}

Light microscopy images of the specimens show no significant differences in grain size or fraction of $\delta$-phase, carbides or nitrides (see Figure 4). The grain size of the $\gamma$-matrix, determined with the line intersection method, is approximately $6-8 \mu \mathrm{m}$ for all conditions. The volume fraction of the $\delta$-phase is approximately $1-1.5 \%$. The volume fractions of carbides and nitrides are negligible. 


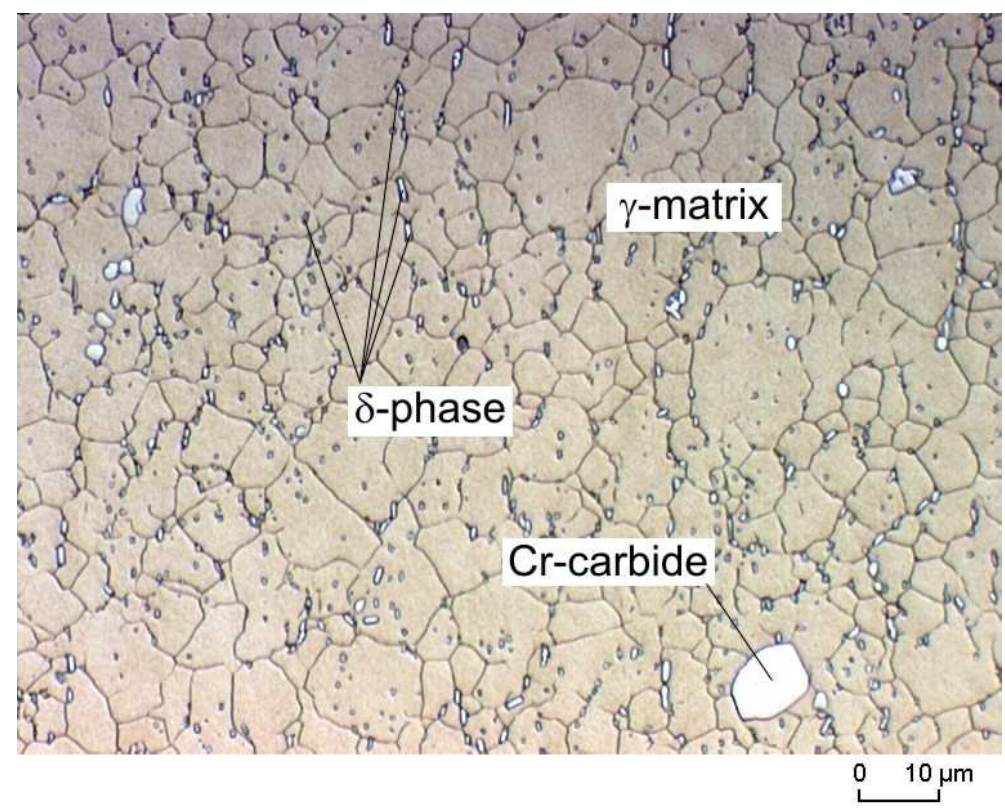

Figure 4: Light microscopic image of a low-strain-rate specimen before aging.

Using transmission electron microscopy small particles $(\approx 1 \mathrm{~nm})$ can be detected in specimens exposed to high strain rates in the as-forged, water quenched material. In specimens deformed at high strain rate followed by air cooling the particles are slightly larger (5 nm) than in the water quenched specimens (Figure 5). Using diffraction methods the particles

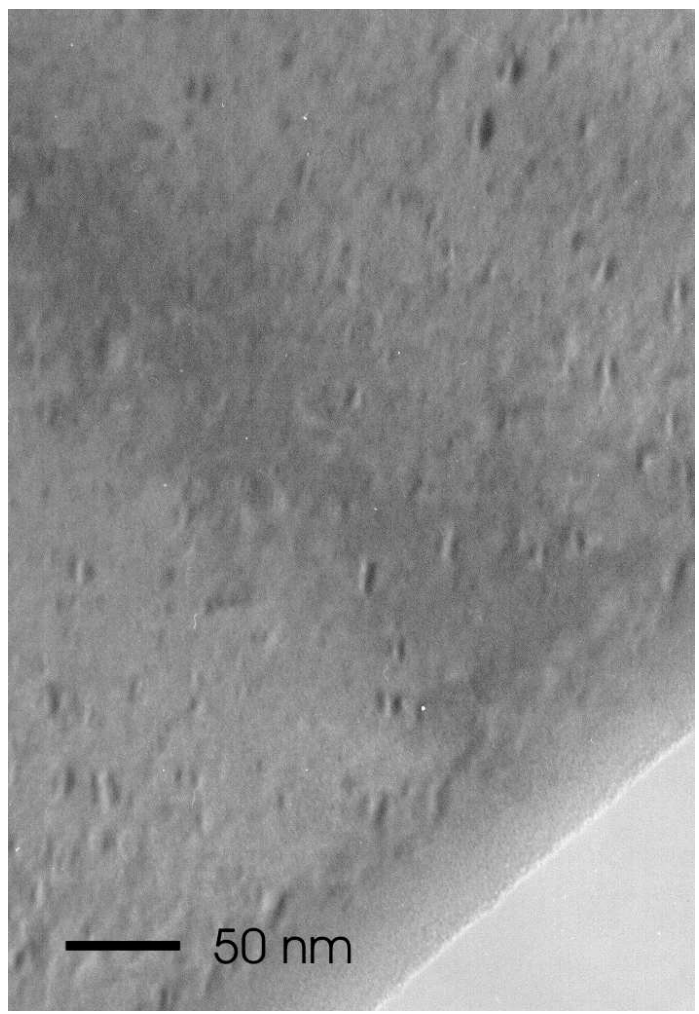

Figure 5: Transmission electron microscopic image of the particles found in high-strain-rate specimens (air cooled) before aging.

are identified as $\gamma^{\prime \prime}$-phase (Figure 6 and $[4,11]$ ). Neither in the air cooled nor in the water 
quenched specimens exposed to low strain rates particles were found. During the subsequent aging the $\gamma^{\prime \prime}$-particles grow as shown in Figure 7.

The existence of the $\gamma^{\prime \prime}$-particles in the as-forged material exposed to high strain rates is

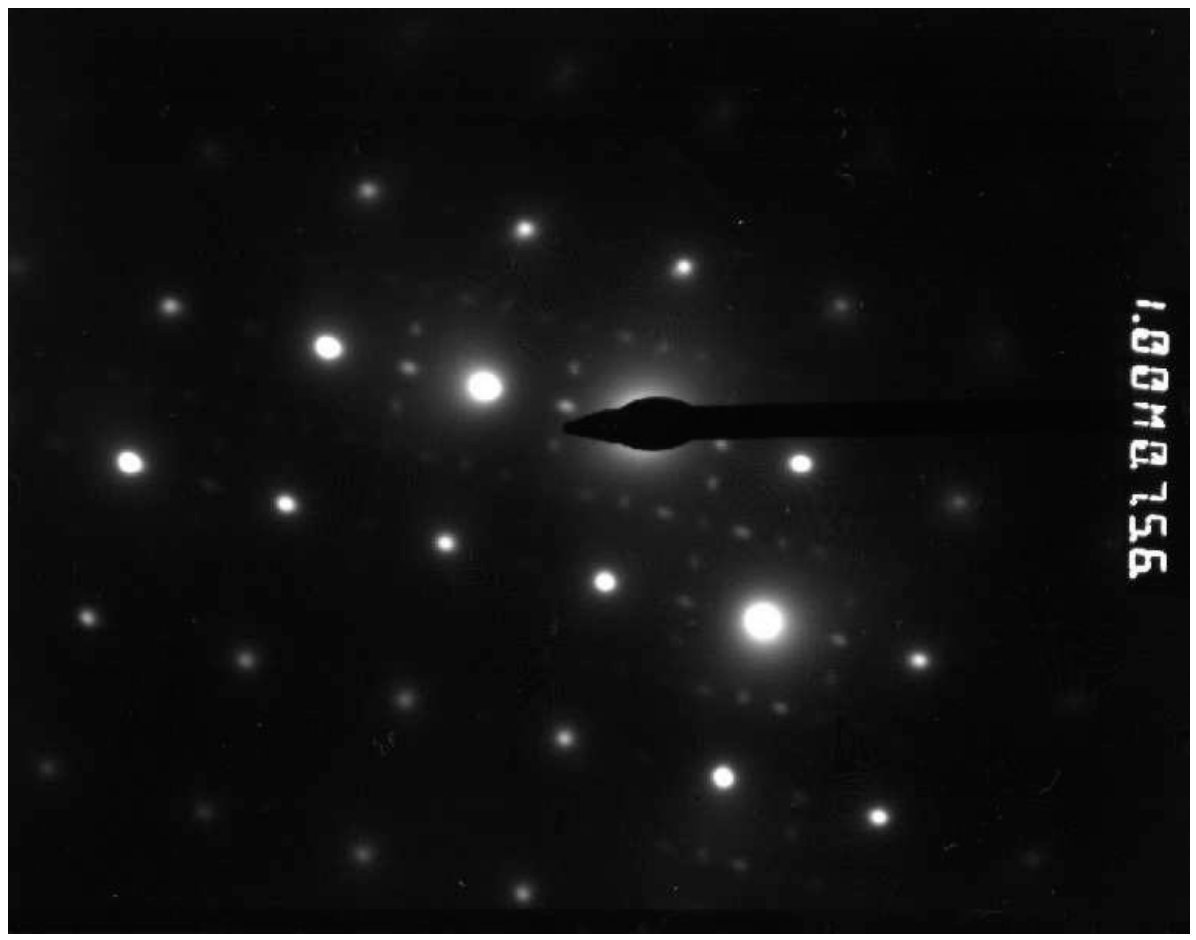

Figure 6: Diffraction pattern of the $\gamma^{\prime \prime}$-particles under beam direction [110].

assumed to be the reason for the improved strength of this material condition.

The strengthening effect of precipitates is usually described with the equations of Orowan and Kelly-Fine [12]:

$$
\begin{array}{cl}
\Delta H V=\alpha G b \frac{\sqrt{f}}{d_{\mathrm{T}}} & \text { Orowan, } \\
\Delta H V=\frac{\tilde{E}^{3 / 2}}{b^{2} \sqrt{3 G}} \sqrt{f} \sqrt{d_{\mathrm{T}}} & \text { Kelly }- \text { Fine, }
\end{array}
$$

where $\Delta H V$ is the hardness increment, $\alpha$ is a constant, $G$ is the shear modulus, $b$ is the Burgers-vector, $f$ is the volume fraction of the precipitates and $d_{\mathrm{T}}$ is the precipitates diameter. $\tilde{E}$ is a measure for the particle-dislocation interaction and is roughly $G b|\epsilon|$, if only the parelastic interaction is considered [12]. The size effect $\epsilon$ is related to the size mismatch between matrix and precipitate. Plotting both functions (Figure 8) it can be seen, that for small particles the energy and hence the the stress necassary for bowing out the dislocations between two particles (Orowan-mechanism) becomes very high. Therefore it is well accepted, that small particles are rather cut by dislocations (Kelly-Fine-mechanism). For larger particles the Orowan mechanism is energetically favoured. There exists an optimum particle size $d_{\mathrm{c}}$ defined as intersection of the two curves drawn in Figure 8 and which is associated with the largest possible increase in strength or hardness $\Delta H V$. This optimum particle size $d_{\mathrm{c}}$ for IN 718 can be estimated by combining (1) and (2), i.e.

$$
d_{\mathrm{c}}=\frac{G b^{2}}{\tilde{E}}(\alpha \sqrt{3})^{2 / 3}
$$




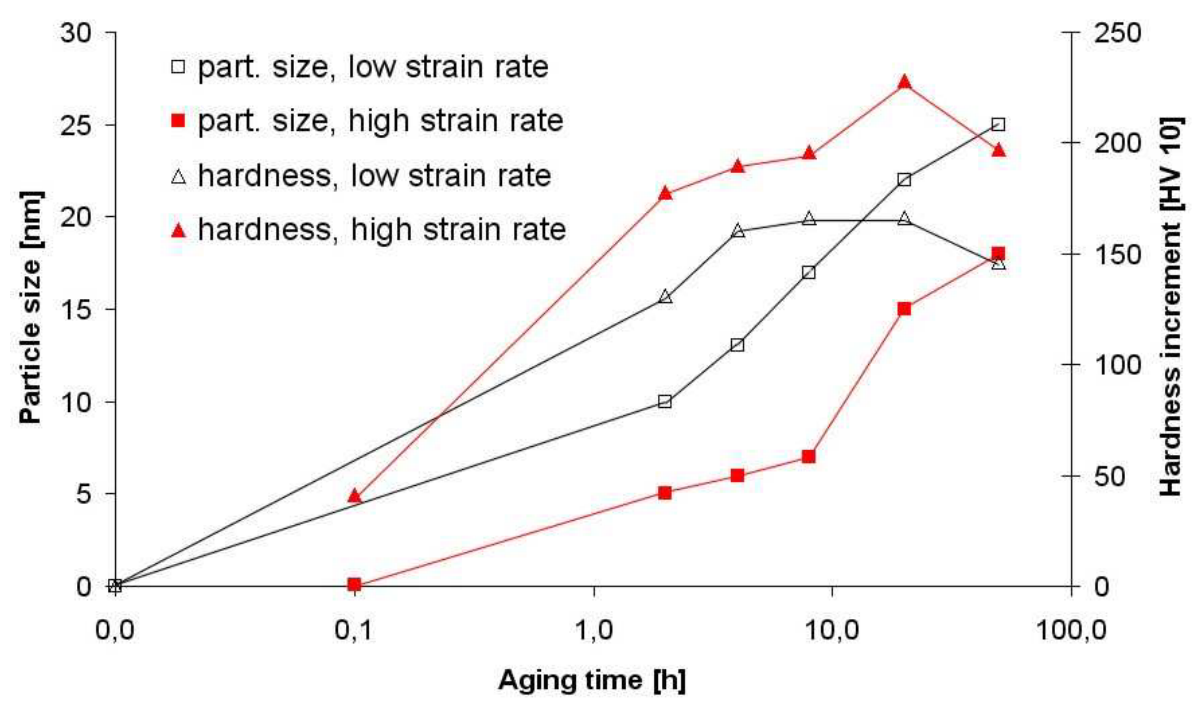

Figure 7: Growth of $\gamma^{\prime \prime}$-particles and hardness increment during the heat treatment at $718^{\circ} \mathrm{C}$.

Putting the constant $\alpha$ to 0.5 , the optimum particle size becomes $7.5 \mathrm{~nm}$ [12]. With this estimation the Orowan-mechanism becomes prominent for particles above $7.5 \mathrm{~nm}$ in size. Hardness is expected to be higher for the as-forged high-strain-rate specimens because of the existing $\gamma^{\prime \prime}$-particles. Furthermore an increasing hardness up to a particle size of $d_{\mathrm{c}}$ and a decreasing hardness for particle sizes exceeding $d_{\mathrm{c}}$ is expected. The results of hardness measurements are plotted also in Figure 7. The existence of the $\gamma^{\prime \prime}$-phase in the as-forged high-strain-rate specimens is the explanation for the higher hardness against the as-forged low-strain-rate specimens. At a first glance it seems surprising that the hardness increases for all specimens even if the particle size exceeds $d_{\mathrm{c}}$. Until 20 hours of heat treatment at $718^{\circ} \mathrm{C}$ the hardness increases to approximately $500 \mathrm{HV} 10$ for the high-strain-rate specimens. After 50 hours the hardness decreases to $470 \mathrm{HV} 10$ due to overaging. The hardness of the lowstrain-rate specimens reaches its maximum of $440 \mathrm{HV} 10$ after 8 hours, before the hardness decreases to $420 \mathrm{HV} 10$ after 50 hours at $718^{\circ} \mathrm{C}$.

Relation (3) shows, that $d_{\mathrm{c}}$ is independent of the volume fraction $f$ of the precipitates. The increment $\Delta H V$, however, depends of $\sqrt{f}$, see (1) and (2). Hence, it is the volume fraction of $\gamma^{\prime \prime}$ that has to be taken into account also to understand the hardness vs. aging time curves in Figure 7. Figure 9 shows the volume fraction of the $\gamma^{\prime \prime}$-particles vs. aging time as obtained from bright-field TEM images. For these investigations, the areal fraction of the $\gamma^{\prime \prime}$-particles in a test area was determined from images like Figure 5. For a large number of measurements and representative test areas the volume fraction of particles can be estimated from the areal fraction of the particles in a 2D-image. Bright-field images show only two of three equally probable orientations of the $\gamma^{\prime \prime}$-precipitates. Diffraction patterns like Figure 6 reveal, that all three orientations occur in the specimens [4]. Therefore, the measured area fraction was multiplied by $3 / 2$ to take the third orientation variant into account. While both forging routes result in the same volume fraction of about $13 \%$ after long aging times ${ }^{1}$, the kinetics of precipitation differ significantly for short times. Forging at high strain rate produces a high density of lattice defects that can act as nucleation sites for $\gamma^{\prime \prime}$-precipitates. Hence, aging the material after forging on a screw press results in a much finer dispersion of small particles than processing on a hydraulic press does. The precipitates of the low strain

\footnotetext{
${ }^{1}$ The $\mathrm{Nb}$-content of IN 718 allows for $14 \% \mathrm{Ni}_{3} \mathrm{Nb}$-phases. Considering the investigated fraction of $1 \%$ of $\delta$-phase an equilibrium amount of $13 \%$ of $\gamma^{\prime \prime}$ is possible.
} 


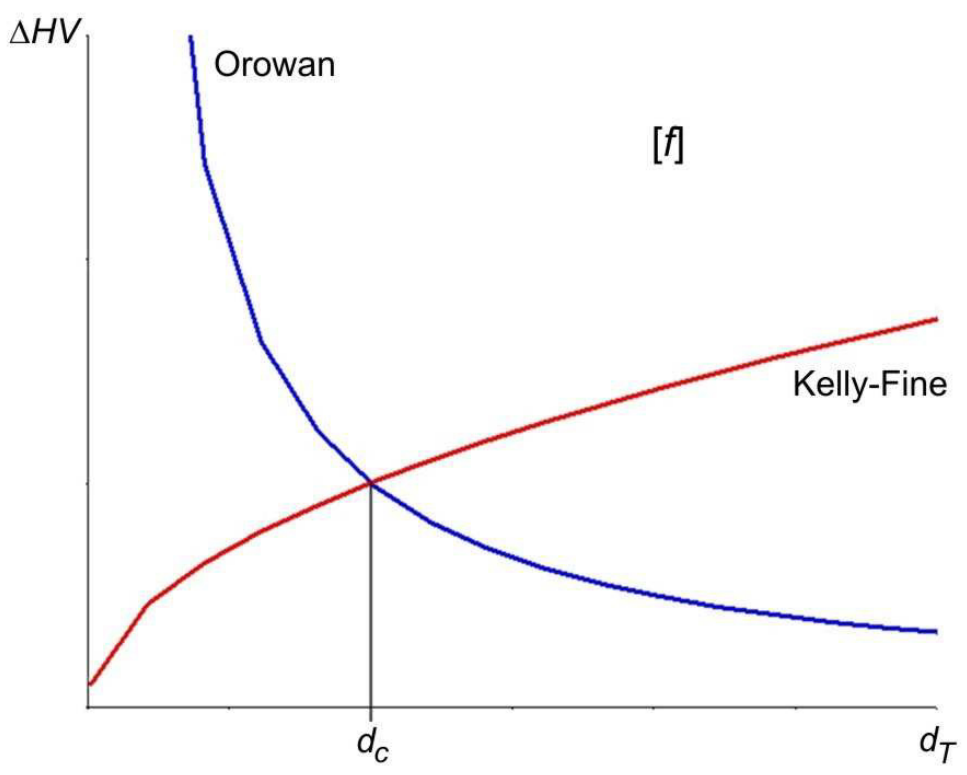

Figure 8: Schematical plot of hardness increment over particle size according to Orowan and to Kelly-Fine. The volume fraction of the particles is constant.

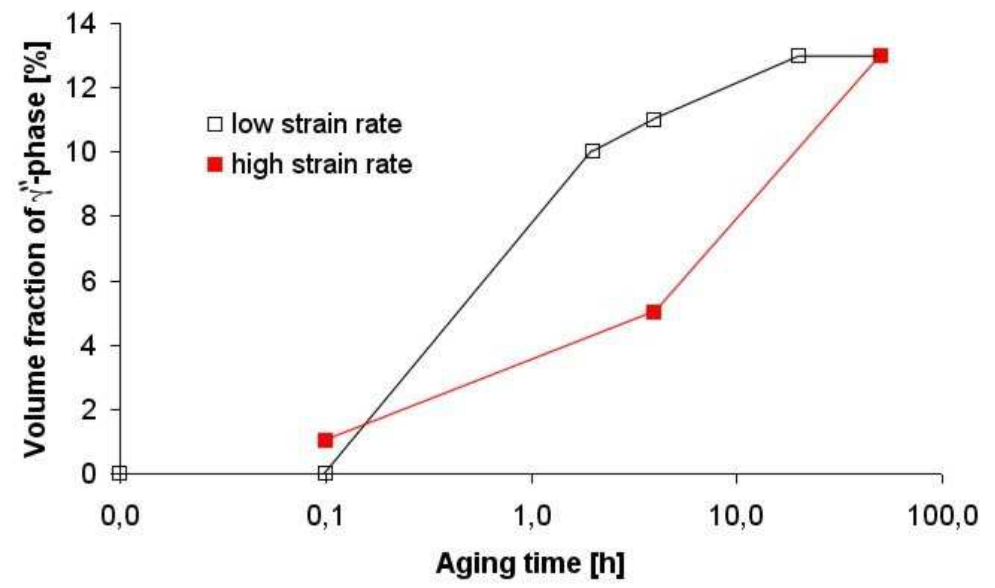

Figure 9: Volume fraction of the $\gamma^{\prime \prime}$-particles vs. aging time (at $718^{\circ} \mathrm{C}$ ).

rate material tend to coarsen even after short precipitation times resulting in $f>11 \%$ after 8 hours at $718^{\circ} \mathrm{C}$. After the same time of exposure to $718^{\circ} \mathrm{C}$ nucleation of new $\gamma^{\prime \prime}$-precipitates still dominates the precipitation process in the screw press forged material. The volume fraction of the $\gamma^{\prime \prime}$-precipitates is $f=5 \%$. Therefore, the fully precipitated states will differ with respect to particle size and density. The effect of this can be seen clearly in Figure 10, which shows the increase in hardness $\Delta H V$ as function of the $\gamma^{\prime \prime}$-particle size of both, high-strain-rate and low-strain-rate specimens. The hardness increment is calculated as the difference between the measured hardness and a reference value, which is set to $274 \mathrm{HV} 10$ being the hardness of the as-forged low-strain-rate-specimens. A reference value for the asforged high-strain-rate specimens cannot be determined, since the microstructure contains about $1 \%$ of $\gamma^{\prime \prime}$-precipitates even without an aging treatment. The curves drawn in Figure 10 are calculated from equations (1) and (2) for the volume fractions of the $\gamma^{\prime \prime}$-precipitates indicated in the legend of the diagram. The precipitation of $\gamma^{\prime \prime}$ in specimens forged at low strain rate is almost completed after approximately 8 hours of heat treatment. Subsequently, 


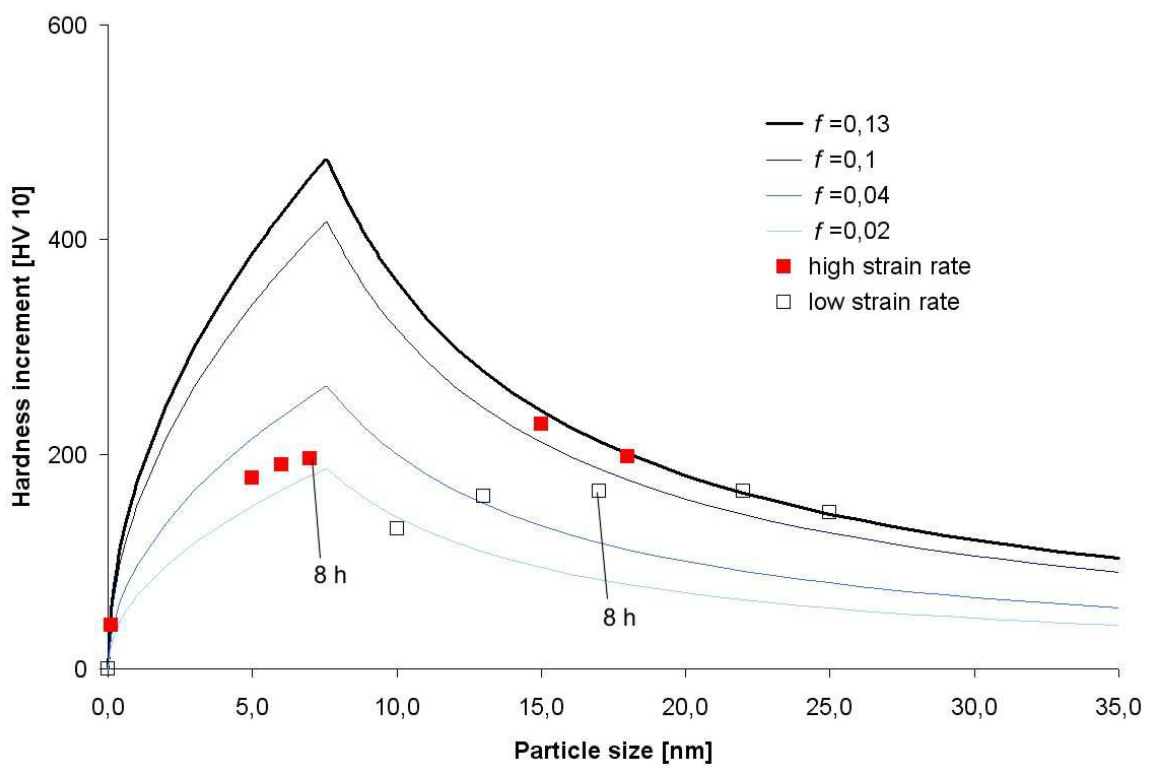

Figure 10: Hardness increase with growing particles. The thick curve for $f=0.13$ shows the maximum volume fraction of $\gamma^{\prime \prime}$-phase in IN 718 in the presence of $1 \%$ of $\delta$-phase.

the particles coarsen and their effectiveness against dislocation movement becomes weaker and therefore $\Delta H V$ decreases again. In contrast, precipitation of $\gamma^{\prime \prime}$ in the screw press forged specimens is far from being completed after 8 hours, see Figure 9. Forging IN 718 on a screw press and then exposing the material to the prescribed aging treatment ( 8 hours at $718^{\circ} \mathrm{C}$ ) generates a near optimum dispersion of $\gamma^{\prime \prime}$-precipitates at relatively low volume fractions of $\gamma^{\prime \prime}$. Annealing the material for 20 hours instead, ends in an equilibrium volume fraction, which is associated with the highest hardness of all microstructures investigated. This behaviour is due to the fine dispersion of the $\gamma^{\prime \prime}$-precipitates.

\section{Conclusions}

In this work it is shown, that the $\gamma^{\prime \prime}$-phase starts to precipitate in specimens exposed to high strain rates immediately after forging. This does not occur in specimens exposed to low strain rates. The current TTT diagram (Figure 11) does not predict precipitation prior to at least 0.1 hours of isothermal annealing at $870^{\circ} \mathrm{C}$. It has been proven that higher strain rates cause an earlier precipitation and finer dispersion of the $\gamma^{\prime \prime}$-phase. Therefore, it is suggested, that the TTT diagram has to be modified by including curves for $\gamma^{\prime \prime}$-precipitation in IN 718 exposed to high strain rates (dashed curves in Figure 11). Investigations dealing with these modifications are in progress. 


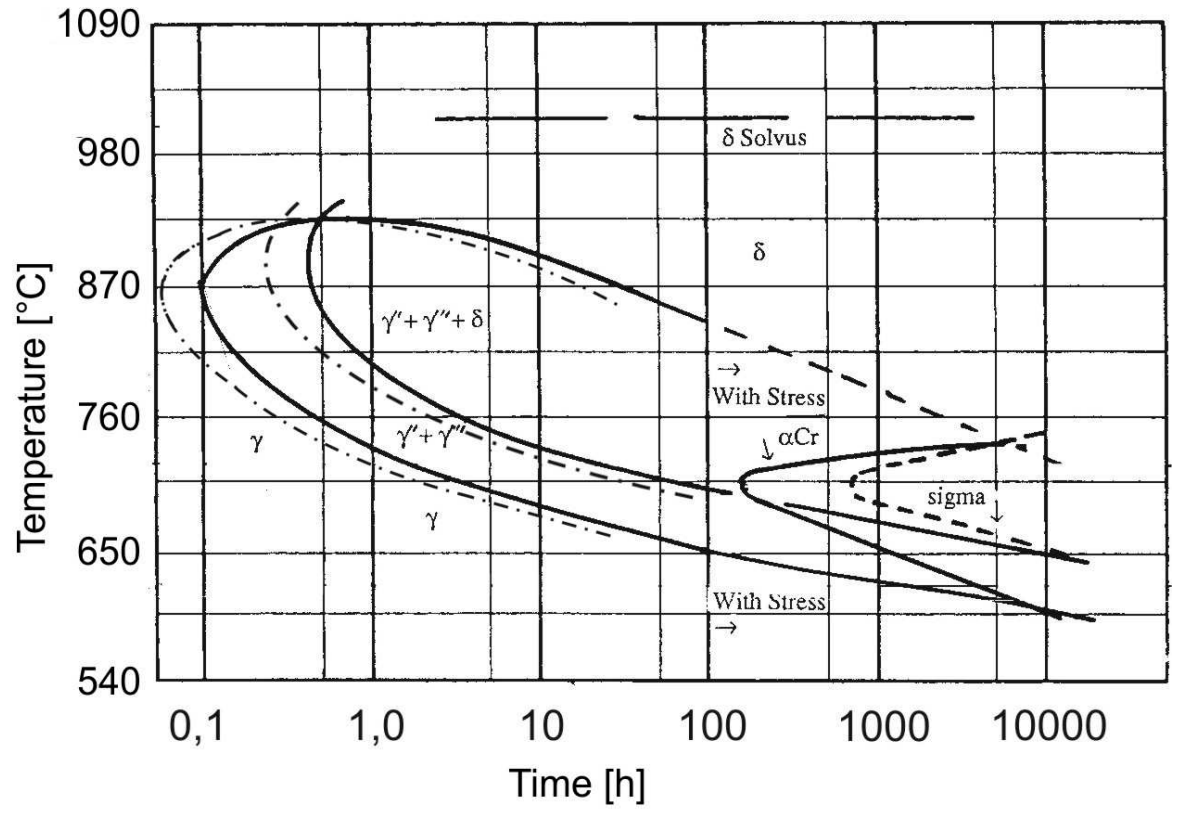

Figure 11: Current TTT-Diagram of IN 718 [2]. The dash-dot curves are the supposed modification for IN 718 forged at high strain rates. 


\section{References}

[1] W. Horvath et al. The effectiveness of direct aging on Inconel 718 forgings produced at high strain rates as obtained on a screw press. In E.A. Loria, editor, Superalloys 718, 625, 706 and Various Derivates, pages 223-228. The Minerals, Metals \& Materials Society, 2001.

[2] A. Oradei-Basile and J.F. Radavich. A current T-T-T diagram for wrought alloy 718. In E.A. Loria, editor, Superalloys 718, 625 and Various Derivates, pages 325-335. The Minerals, Metals \& Materials Society, 1991.

[3] S.M. Copley and B.H. Kear. A dynamic theory of coherent precipitation hardening with application to Nickel-base superalloys. Transactions of the Metallurgical Society of AIME, 239:984-992, 1967.

[4] R. Cozar and A. Pineau. Morphology of $\gamma^{\prime}$ and $\gamma^{\prime \prime}$ precipitates and thermal stability of Inconel 718 type alloys. Metallurgical Transactions, pages 47-59, 1973.

[5] I. Kirman. Precipitation in the Fe-Ni-Cr-Nb system. Journal of the Iron and Steel Institute, pages 1612-1618, 1969.

[6] L. Renhof and E. Werner. Modul 6 - Direct aged IN 718. Technical Report Nr. 6/1, CD-Laboratorium für moderne Mehrphasenstähle, München, 2002.

[7] L. Renhof and E. Werner. Modul 6 - Direct aged IN 718. Technical Report Nr. 6/2, CD-Laboratorium für moderne Mehrphasenstähle, München, 2003.

[8] L. Renhof and E. Werner. Modul 6 - Direct aged IN 718. Technical Report Nr. 6/3, CD-Laboratorium für moderne Mehrphasenstähle, München, 2004.

[9] G. Petzow. Metallographisches, keramographisches, plastographisches Ätzen. Gebrüder Borntraeger, 1994.

[10] G. Saller. Gefügecharakterisierung von ausgewählten Nickelbasis-Superlegierungen. Master's thesis, Montanuniversität Leoben, 1999.

[11] I. Kirman and D.H. Warrington. Identification of the strengthening phase in Fe-Ni-CrNb alloys. Journal of the Iron and Steel Institute, pages 1264-1265, 1967.

[12] P. Haasen. Physikalische Metallkunde. Springer Verlag, 1994. 